\title{
A Review on the Lignin Biopolymer and Its Integration in the Elaboration of Sustainable Materials
}

\author{
Francisco Vásquez-Garay ${ }^{1, *}$, Isabel Carrillo-Varela ${ }^{2}$, Claudia Vidal ${ }^{2}$, Pablo Reyes-Contreras ${ }^{1}$ (D), Mirko Faccini ${ }^{1}$ \\ and Regis Teixeira Mendonça 2,3 (D) \\ 1 Centro de Excelencia en Nanotecnología (CEN), Santiago 7500724, Chile; preyes@leitat.cl (P.R.-C.); \\ mfaccini@leitat.org (M.F.) \\ 2 Laboratorio de Recursos Renovables, Centro de Biotecnología, Universidad de Concepción, \\ Concepción 4030000, Chile; iscarrillo@udec.cl (I.C.-V.); clauvidal@udec.cl (C.V.); rteixeira@udec.cl (R.T.M.) \\ 3 Facultad de Ciencias Forestales, Casilla 160-C, Universidad de Concepción, Concepción 4030000, Chile \\ * Correspondence: fvasquez@leitat.cl
}

check for updates

Citation: Vásquez-Garay, F.; Carrillo-Varela, I.; Vidal, C.;

Reyes-Contreras, P.; Faccini, M.; Teixeira Mendonça, R. A Review on the Lignin Biopolymer and Its Integration in the Elaboration of Sustainable Materials. Sustainability 2021, 13, 2697. https://doi.org/ $10.3390 /$ su13052697

Academic Editor: Mariusz Maminski

Received: 18 January 2021

Accepted: 23 February 2021

Published: 3 March 2021

Publisher's Note: MDPI stays neutral with regard to jurisdictional claims in published maps and institutional affiliations.

Copyright: (c) 2021 by the authors. Licensee MDPI, Basel, Switzerland This article is an open access article distributed under the terms and conditions of the Creative Commons Attribution (CC BY) license (https:// creativecommons.org/licenses/by/ $4.0 /)$.

\begin{abstract}
Lignin is one of the wood and plant cell wall components that is available in large quantities in nature. Its polyphenolic chemical structure has been of interest for valorization and industrial application studies. Lignin can be obtained from wood by various delignification chemical processes, which give it a structure and specific properties that will depend on the plant species. Due to the versatility and chemical diversity of lignin, the chemical industry has focused on its use as a viable alternative of renewable raw material for the synthesis of new and sustainable biomaterials. However, its structure is complex and difficult to characterize, presenting some obstacles to be integrated into mixtures for the development of polymers, fibers, and other materials. The objective of this review is to present a background of the structure, biosynthesis, and the main mechanisms of lignin recovery from chemical processes (sulfite and kraft) and sulfur-free processes (organosolv) and describe the different forms of integration of this biopolymer in the synthesis of sustainable materials. Among these applications are phenolic adhesive resins, formaldehyde-free resins, epoxy resins, polyurethane foams, carbon fibers, hydrogels, and 3D printed composites.
\end{abstract}

Keywords: lignin; pulping processes; lignin valorization; biocomposites; sustainable materials; biomaterials; 3D-printing

\section{Introduction}

Lignin is an amorphous biopolymer with a phenolic macromolecular structure, that can be extracted from wood, annual plants, and agricultural residues [1,2]. The lignin content varies according to the lignocellulosic source, plant, species, genetics, and environmental conditions, but in general, its amount is in the range of $20 \%-30 \%$ of the biomass dry weight [3].

Industrial processes are designed to extract lignin from lignocellulosic materials to convert the other components, such as cellulose, into accessible and purified fibers for different purposes. The industrial sector that uses these processes with great economic profit is the pulp and paper, which employing chemical cooking of wood, solubilizes lignin and converts cellulose into a commodity of high commercial value [4]. The production of lignin worldwide reaches 70 million tons per year, which would make its use feasible for several industrial applications [5].

Most large-scale industrial processes that use plant polysaccharides have burned lignin to generate the energy needed for the industrial operations [6,7]. Only $2 \%$ of residual lignin has been used for other higher value-added applications [6]. This underutilization motivates the development of engineer lignin-based products of increased commercial value [8]. However, valorization of lignin has some difficulties that are mainly attributed to 
the complexity and recalcitrance of this biopolymer $[7,9]$ and the high heterogeneity, being challenging to predict a stable behavior in advanced material syntheses [6].

Lignin, having a polyphenolic structure, has properties as antioxidant activity, biodegradability, high thermal stability, reactivity, and adhesive properties [10]. Therefore, its use as a versatile chemical would give rise to additional economic benefits for the pulp and paper industry as it can be available in large volumes and at a relatively low cost, compared to phenolic compounds derived from oil [11,12]. However, the wood type and the pulping processes are responsible for the final structure of lignin. A lignin structure highly homogenous is favorable to its integration in novel materials [5].

Currently, there are several applications aimed to take advantage of the chemical properties of lignin such as bioplastics, carbon fibers, lignin-based composites as highperformance materials, polymers with adhesive properties for wood panels, hydrogels, polymer for synthesis of polyurethane foams, and as an additive in mixtures to confer emulsifying or protective properties $[1,10,11,13]$. Otherwise, there is also an interest of lignin conversion in oligomeric or monomeric phenolic compounds, using biotechnological or chemical techniques for depolymerization $[4,13,14]$.

Based on the background available, the objective of this review is to provide fundamental and updated information on lignin chemistry and potential use as polymer or building block for the manufacture of new and sustainable biomaterials.

\section{Lignin Chemistry and Structure}

In the plant cell walls, cellulose microfibrils are organized in defined oriented layers embedded in a hemicellulose and lignin matrix [15]. Within this arrangement in the cell wall, the existence of strong covalent bonds between phenolic compounds and carbohydrates has been suggested [16], where lignin acts as a cementing agent, providing mechanical strength, rigidity, and support for the plant growth. Furthermore, it plays a protective role for polysaccharides, hindering their degradation and acting as a barrier to degradation by bacteria and fungi $[2,17,18]$.

Lignin biosynthesis is part of the phenylpropanoid pathway that also produces secondary metabolites such as tannins, flavonoids, and lignans. The lignin formation process, its biosynthesis and polymerization have been reviewed in detail by Boerjan et al. [19] and Bonawitz and Chapple [20]. The biosynthesis of lignin occurs in vivo via an enzymemediated dehydrogenation polymerization resulting in a cross-linked amorphous material with ether and carbon-carbon linkage types as described by Upton and Kasko [8]. Lignin is mainly made up of three phenylpropanoid precursors, known as monolignols: p-coumaryl alcohol, coniferyl alcohol, and sinapyl alcohol $[2,4,11,12]$ as seen in Figure 1 . The main difference between these three monomers is in the number of methoxy groups attached to the phenolic ring. The p-hydroxyphenyl unit $(\mathrm{H})$ has no methoxy group, the guaiacyl unit $(G)$ has one methoxy group, while the syringyl unit (S) has two methoxy groups $[2,17,21]$. These units are connected by carbon-carbon $(5-5, \beta-5, \beta-1$ y $\beta-\beta)$, and ether ( $\beta-\mathrm{O}-4, \alpha-\mathrm{O}-4$, $4-\mathrm{O}-5)$ linkages [22-24]. The amount and composition of intermonomeric linkage units of lignin varies between different plant taxa, cell types, and cell wall layers $[25,26]$. Softwoods contain mainly G-type lignin, hardwoods contain SG-type lignin, and grasses have HGS-type lignin $[27,28]$. The $\beta-\mathrm{O}-4$ linkage is the most abundant in native lignin, typically accounts $50 \%$ of bonds formed during the biosynthesis reactions, and is one of the most labile bonds, and is readily cleaved to by most pretreatment or depolymerization mechanisms [8,9]. Depolymerized lignin fractions are highly reactive under depolymerization reactions, which leads to condensation or repolymerization of lignin [7]. A representative structure of lignin is show in Figure 2. 
A<smiles>OCC=Cc1ccc(O)cc1</smiles>

B<smiles>COc1cc(C=CCO)ccc1O</smiles>

\section{C}<smiles>COc1cc(C=CCO)cc(OC)c1O</smiles>

Figure 1. Main monolignoles found in the lignin structure. (A) p-coumaryl alcohol; (B) coniferyl alcohol; (C) sinapyl alcohol.

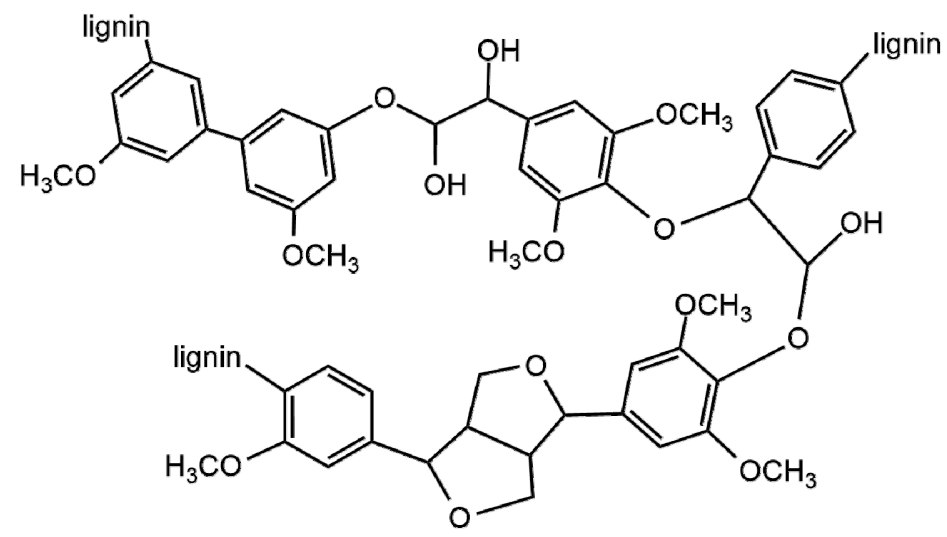

Figure 2. A representation of lignin structure.

\section{Industrial Sources of Lignin}

Different methods have been applied to isolate lignin from lignocellulosic material for industrial applications [11]. Due to the different delignification techniques available and the different plant species used, the lignin recovered from these processes presents differences in terms of its physical and chemical properties, since the structure, size, and molecular weight of the resulting lignin fragments are different $[3,4,13,17,29]$. The most used processes for biomass delignification are kraft, sulfite, and organosolv as seen in Scheme 1. Other less commercial alternatives are pyrolysis, steam explosion, enzymatic hydrolysis, acidolysis, and alkaline hydrolysis [3,12,13,17,29-31]. These methods are different in several parameters that influence the extraction yield, lignin functionality, molar mass, and solubility, among other properties according to the temperature, $\mathrm{pH}$, chemical load, and pressure of the system $[8,30]$. The main processes for obtaining lignin from lignocellulosic materials are detailed below, emphasizing the processes that use sulfur-based chemicals for delignification, such as sulfite and kraft, and sulfur-free, as organosolv processes.

\subsection{Lignosulfonates}

The sulfite process is one of the main industrial sources of commercially available lignin $[12,17,18]$. In this process, pulping is carried out in a varying $\mathrm{pH}$ range from 2 to 13 , which is often based on the cationic composition of the pulping/cooking liquor. In general, most sulfite processes are acidic in nature due to the presence of the sulfonic group and employ magnesium or calcium counterions. The presence of the sulfurous group specifically targets $\beta-\mathrm{O}-4$ and $\mathrm{C} \alpha$ linkages, thus breaking lignin into lower-molecularweight compounds [31]. The degradation mechanism of this process is determined by the $\mathrm{pH}$ of the reaction, which involves the equimolar amount of the sulfite, bisulfite, and sulfur dioxide in the medium [12]. This process can be carried out in acidic, neutral, or alkaline conditions [2]; therefore, there are 4 main processes: (i) acid bisulfite with a $\mathrm{pH}$ between 1-2, (ii) bisulfite with a $\mathrm{pH}$ between $3-5$, (iii) neutral sulfite with a $\mathrm{pH}$ 
between $5-7$, and (iv) alkaline sulfite with $\mathrm{pH}$ between 9-13 [12]. These reactions are generally performed at temperatures of 140 to $160^{\circ} \mathrm{C}[17,32]$. One of the main reactions is the sulfonation of carbon- $\alpha$ in $\alpha-\mathrm{O}-4$ bonds that leads to the rupture of the lignin. The breakdown of $\alpha$-O- 4 bonds is higher compared to $\beta-\mathrm{O}-4$ bonds $[2,12,17]$. Due to the reaction mechanism of sulfite processes, sulfonate-soluble lignin fragments have a high molecular weight compared to lignin obtained from other delignification processes [12]. In the case of softwoods, the average molecular weight (Mw) ranges from 36,000-61,000 Da; while in hardwoods, it ranges from 5700 to $12,000 \mathrm{Da}$ [12]. The lignin fragments recovered from the sulfite spent-liquor are called lignosulfonates, presenting different amounts of sulfonic groups attached to the aliphatic chain and are highly soluble in water [2,17]. Technics such as precipitation, ultrafiltration, chemical destruction of sugars, alcohol fermentation of sugars, followed by distillation of fermentation product can be used to recover lignin from the aqueous mixture [8]. Lignosulfonates are currently used in different industrial fields as dispersants and glues, and their functional properties depend on their weight and molecular distribution, but they are also effective stabilizers in emulsions, and have been used for viscosity control in oil drilling fluids [21].

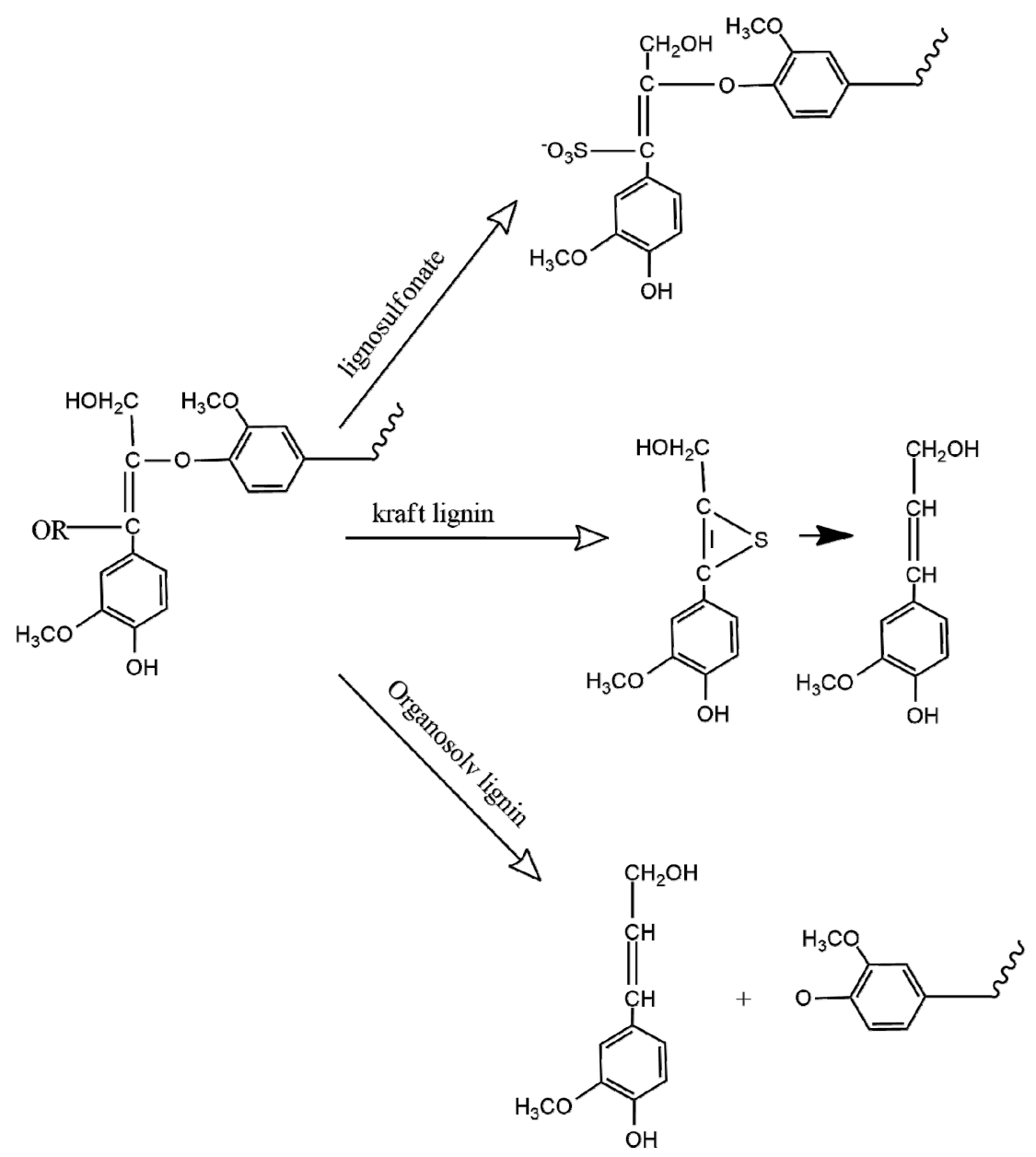

Scheme 1. Main lignin extraction processes revised in this review.

\subsection{Kraft Lignin}

Kraft pulping is the most used process for wood delignification in the pulp and paper industry, accounting for more than $80 \%$ of cellulosic pulp produced worldwide [12,21]. The main active agents in the kraft process are hydroxide and hydrosulfide anions, which are present in the cooking liquor at reaction temperatures between $150-170{ }^{\circ} \mathrm{C}$ and cause mainly the cleavage of $\alpha-\mathrm{O}-4$ and $\beta-\mathrm{O}-4$ bonds in lignin and more than $90 \%$ of delignification takes place if the process is oriented to the production of bleachable-grade cellulose $[17,33,34]$. 
Kraft lignin can be recovered from black liquor through precipitation with mineral acids or carbon dioxide at controlled $\mathrm{pH}[3,17,35]$. Even though Kraft lignin is obtained from a process that involves a high amount of sulfur, the recovered lignin only contains between $1-2 \%$ residual sulfide. This lignin, unlike lignosulfonates, contains a high percentage of phenolic hydroxyl groups, due to the breakdown of the $\beta-\mathrm{O}-4$ ether bonds $[1,12,17]$. The molecular weight $(\mathrm{Mw})$ of the recovered Kraft lignin varies according to the origin; from hardwoods, the average molecular weight $(\mathrm{Mn})$ is between 1000 and $4000 \mathrm{Da}$ and from softwoods, the molecular weight is approximately 20,000 Da [3,12]. Kraft lignin can be solubilized in polar organic solvents and in alkaline solutions $[3,21]$.

\subsection{Organosolv Lignin}

The mechanism of the organosolv processes is based on the extraction of lignin from lignocellulosic materials using polar organic solvents alone or in mixtures with water in different proportions. Through these processes, the removal of lignin results from the breaking of $\beta-\mathrm{O}-4$ bonds to a greater extent [11]. The most widely used solvents in the organosolv processes are ethanol, formic acid, methanol, acetic acid, and acetone [1,3,12,17,36].

The lignin recovered from the organosolv process can have different chemical properties and structures depending on the type of solvent used; some of the most important chemical properties are the polarity, molecular weight, and availability of hydroxyl groups $[11,12,17]$. The characteristics of the recovered lignin will also depend on the raw material used and the presence of catalysts $[12,36,37]$. Organosolv lignin is a high-quality lignin, with higher purity compared to other types of lignins since it is sulfur-free, presenting a homogeneous structure due to its low polydispersity [17]. It also has a higher availability of free phenolic hydroxyl groups, low molar mass, and low amount residual carbohydrates $[1,11,38]$. This type of lignin can be recovered from the organosolv black liquor by flash distillation or acid precipitation to $\mathrm{pH} 2-3$. It is soluble in water-ethanol mixtures, in polar solvents and alkaline media $[1,3,12]$.

\section{Lignin Applications}

Lignin has been deeply studied for its potential integration in different new materials as a sustainable replacement for some petroleum derivatives and chemicals $[5,6,14,39]$. Due to its polyphenolic structure, it has properties that could be useful in a wide spectrum of composite materials such as adhesive resins, polyolefins, polyurethane foams, epoxy resins, packaging materials, unsaturated polyester, material filler, and phenolic monomers [10]. Lignin can be both integrated into a matrix to give it new properties, without any chemical modification or be chemically modified for the synthesis of chemical compounds, prepolymers, and polymers $[1,39]$. The conversion of lignin to high value-added products plays a key role in the economic viability of a biorefinery. The study of lignin conversion mechanisms has established the catalytic routes for the generation of products such as aromatic chemical reagents and biobased materials. Some of these applications are detailed below, emphasizing phenolic adhesive resins, epoxy resins, polyurethane foams, carbon fibers, hydrogels, and 3D printed biocomposites as shown in Scheme 2.

\subsection{Lignin-Based Phenolic Resins}

Phenol-formaldehyde (PF) resins are the most widely used adhesive in the wood panel industry. These resins gave wood products excellent adhesive strength, thermal stability, moisture resistance, preventing from delamination or degradation [40-43]. PF resins can be synthesized under acidic or basic conditions, each being named as novolac or resol resins, respectively [44]. As phenol is a petrochemical compound, PF resins costs are highly dependent on fluctuations in oil prices. Under this scenario, the search for the partial or total substitution of phenol by a cheaper compound from renewable origin has been the interest of several investigations [40-46]. 


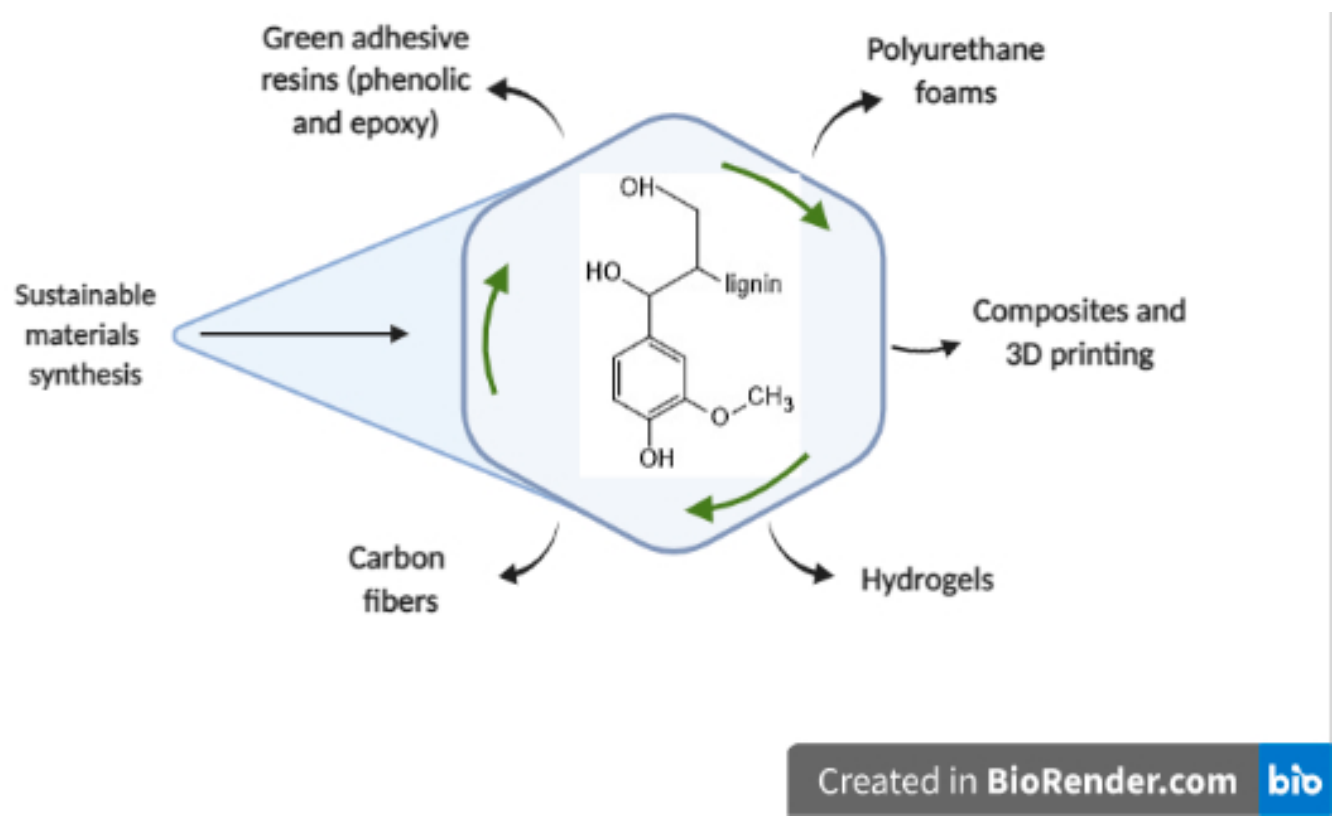

Scheme 2. Summary scheme of sustainable materials applications described in this review.

The use of lignin for the synthesis of adhesives has been one of the most studied applications due to its polyphenolic structure and large number of available hydroxyl groups that provided reactivity and adhesive properties [42,43,45-48]. Lignin-based phenolic resins have been studied for application in plywood, medium density fiberboard (MDF), particle board (PB), and oriented strand board (OSB) [40,41]. However, lignin has been shown to have low reactivity towards formaldehyde compared to phenol and only can be used to partially replace phenol in adhesive formulations. Çetin and Özmen [40] were able to synthesize lignin-phenol-formaldehyde (LPF) resin with $20-30 \%$ of organosolv lignin replacing phenol, obtaining viscosities of $200-250 \mathrm{cP}$ and curing temperature of $150^{\circ} \mathrm{C}$, the desired range for a resol-type resin. Similar results were obtained by Wang et al. [45] that replaced between $25-75 \%$ of phenol by softwood organosolv lignin in a resol type resin at $150-175^{\circ} \mathrm{C}$ curing temperature and thermal stability below $60 \%$. Zhang et al. [41] also prepared LPF resins substituting from $10 \%$ to $70 \%$ of phenol for lignin from biorefinery residues and optimal results were achieved when $50 \%$ substitution was used.

On the other hand, some investigations indicate the higher percentages of substitution could be reached only after a chemical modification of lignin, as is hydroxymethylation with glyoxal in an alkaline medium [49]. In addition, demethylation and phenolation were identified as strategies to increase lignin reactivity towards formaldehyde [1,21]. Kalami et al. [43] showed that a total replacement of phenol by lignin in PF resol type resins is possible using lignin from corn stover pretreated with dilute acid and extracted with alkali. The dry mechanical resistance and curing temperature of the resins with total replacement were $3.4 \mathrm{MPa}$ and $203^{\circ} \mathrm{C}$, comparable to $3.6 \mathrm{MPa}$ and $193{ }^{\circ} \mathrm{C}$ of the commercial PF resin, respectively.

Formaldehyde-based wood adhesives such as urea-formaldehyde and phenol-formaldehyde are the resins mostly used in the production of wood boards, such as plywood and particle boards $[50,51]$. However, there are concerns regarding formaldehyde use since it causes skin irritation and respiratory discomfort. Prolonged exposure may result in spontaneous abortion, memory injury, nasopharyngeal cancer, and leukemia. High formaldehyde prices also have a negative impact on the wood board manufacturing costs [50-52]. The development of formaldehyde-free adhesives using lignin would be also of great benefit to the wood-board industry and human health. Liu and Li [53] developed a formaldehyde-free adhesive using demethylated Kraft lignin (DKL) and polyethyleneimine (PEI), where it was proposed that the hydroxyl groups of DKL can be oxidized to quinones 
during the curing process generating covalent links with PEI. The synthesized resins were optimally cured at $120{ }^{\circ} \mathrm{C}$ within 5 min and 1:1 ratio of DKL/PEI, resulting in a shear strength value on dry measurement of $7 \mathrm{MPa}$ versus $6 \mathrm{MPa}$ when compared with a commercial phenol-formaldehyde resin. Furthermore, a molecular weight between 70,000 to $750,000 \mathrm{~g} / \mathrm{mol}$ PEIs could have a small effect on the strength and water resistance in the lap-shear specimens resulting in values within a range of 4.5 and $7 \mathrm{MPa}$. Recently, Gong et al. [52] reported a high-performance lignin-based adhesive without formaldehyde using acetonitrile extracting lignin, modified by phenol (PAEL) and polyvinylpyrrolidone (K30). The optimal conditions for this preparation were using a mole ratio of lignin to phenol 1:2, mole ratio of PAEL to K30 1:0.4, at $80^{\circ} \mathrm{C}$ for $3 \mathrm{~h}$. Mechanical tests of shear and water resistance in plywood (after soaking for $24 \mathrm{~h}$ ), where 1.70 and $1.02 \mathrm{MPa}$, respectively, complying standards for plywood properties. Lately, Younesi-Kordkheili and Pizzi [54] have described a method to synthesis a resin using urea, lignin, and glyoxal for plywood panels. The resin of urea-lignin-glyoxal (ULG), a phenolic resin, was improved by adding small epoxy resin quantities $(1,3$, and $5 \% w / w)$. The results described in this work show that the plywood bonded with this resin presented a better tensile shear strength than the control resin without epoxy content. The resin that contained 5\% of epoxy resin exhibited the highest panel dry strength with 1.7 vs. $0.43 \mathrm{MPa}$ observed in the plywood bonded with the control resin. The resin with $5 \%$ of epoxy content presented the highest panel wet strength with 1.29 vs. $0.2 \mathrm{MPa}$ in the plywood bonded with the control resin. The addition of epoxy in the ULG resin decreased water adsorption from $15 \%$ to $6 \%$ [54].

\subsection{Lignin-Based Epoxy Resins}

Epoxy resins are used in different applications as they have excellent properties of hardness and dimensional stability; therefore, they are used in fiber-reinforced composite materials, adhesives, additive in lubricating oils, polyurethane foams, surface coatings, among others [44,55-57]. Epoxy resins are thermoset materials, where epoxy structures are reactive towards the other chemical forms, mainly hydroxyl groups [44]. Epoxy resins are synthesized using bisphenol A (BPA), a compound obtained from the petrochemical industry and also used to produce polycarbonates and plastics BPA with a worldwide production of approximately 6.8 million tons [58-61]. The synthesis of this resin is based on the reaction between bisphenol A (BPA) and epichlorohydrin, giving rise to bisphenol A diglycidyl ether (DGEBA), the main precursor of epoxy resins [44,56,62]. Unfortunately, according to authors such as Vandenberg et al. [58], Aouf et al. [61], and Huang et al. [59], BPA can be a highly harmful compound for the environment and human health, which has been proven as carcinogen. When absorbed by the organism, BPA could increase the risk of obesity, diabetes, and cardiac disorders [61]. Therefore, replacing BPA with compounds of natural origin could become a desirable and viable alternative.

El Mansouri et al. [49] carried out chemical epoxidation with epichlorohydrin and modified Kraft lignin by methylolation and glyoxalation in replacement of BPA. It was shown that using methylolated lignin, higher epoxidation indexes $(3.85 \%)$ were achieved than with glyoxylated (3.1\%) or unmodified Kraft lignin (2.45\%) with $82 \%$ epoxidation yield using lignin $/ \mathrm{NaOH}$ ratio $1 / 3$, at $70{ }^{\circ} \mathrm{C}$ for $3 \mathrm{~h}$ of reaction. Jablonskis et al. [63] used softwood Kraft lignin with epichlorohydrin and $\mathrm{KOH}$ as alkaline catalyst in dimethyl sulfoxide solution. Up to $10 \%$ of a BPA was replaced by lignin, resulting in a resin with high thermal stability, with $50 \%$ weight degradation at $390{ }^{\circ} \mathrm{C}$, similar value to that obtained with a reference BPA-based epoxy resin. In addition, an increase in the Young's modulus was observed in epoxidized resins cured with lignin, resulting in a value of $3.36 \mathrm{GPa}$ using $10 \%$ of lignin versus $2.91 \mathrm{GPa}$ with BPA-based epoxy resin.

Aouf et al. [56] proposed a novel chemo-enzymatic mechanism using immobilized enzyme lipase B (Novozyme 435), hydrogen peroxide, and caprylic acid to carry out the epoxidation of vanillic acid hydroxyl groups in replacement of BPA, achieving conversion efficiency of $87 \%$ after $48 \mathrm{~h}$ at $40{ }^{\circ} \mathrm{C}$. This catalytic method demonstrated a good performance in the epoxidation of the allylic double bonds compared to with the chemical 
mechanism using the hazardous peracid $\mathrm{mCPBA}$, where the highest epoxidation value reached was $75 \%$ using vanillic acid as raw material. Kraft and organosolv lignins were also used for chemo-enzymatic epoxidation, where the first step was the allylation of the available hydroxyl groups of lignin, followed by the enzymatic reaction with immobilized lipase B (Novozyme 435) and a fatty acid to produce oxiranes rings (epoxy groups) [57]. This study reports conversion yields to epoxy groups of $90 \%$ and $55 \%$ for organosolv and Kraft lignin, respectively. Regarding the residual enzymatic activity, it was determined that it is mostly reversible when Kraft lignin is used as starting material, however, the exposure of the enzyme to concentrations of $6 \mathrm{M}$ of hydrogen peroxide during $12 \mathrm{~h}$ reaction would cause the loss of enzymatic activity through denaturation. These studies reinforce the potential use of low molar mass lignin to produce epoxy resins, where it could even play an important role in the curing process as hardening agent $[12,57]$.

\subsection{Lignin-Based Polyurethane Foams}

Polyurethane or polyurethane foams are the most versatile type of materials used, with applications as an interior material for transport media, roof and floor insulation, medical use material, as co-reactive adhesive, use in thermoplastics, as sealants of flats, among others. These foams are synthesized through the reaction between isocyanate and hydroxyl groups. It has been proposed that due to its phenolic nature, lignin could provide the necessary hydroxyl groups and replace polyols conventionally used in the industry of these foams [12,35,44,64]. Pan and Saddler [65] replaced the commercial polyol (Voranol 270) with organosolv lignin from hardwood and Kraft lignin from softwood. Authors carried out preparations to replace the use of Voranol 270 from $19 \%$ to $23 \%(w / w)$ with Kraft lignin. It was shown that lignin effectively generated crosslinking to obtain rigid polyurethane foams, however, the densities obtained were higher than those obtained with commercial foams. The use of $19 \%(w / w)$ of Kraft lignin in the formulations resulted in the desired decrease in the density of the product $\left(100 \mathrm{~kg} / \mathrm{m}^{3}\right)$. The density of the foam increased with the higher proportion of Kraft lignin, generating the formation of unwanted granules in the foaming process [65].

Various authors have also suggested that lignin should be modified for use in foams, with the aim of improving its reactivity and solubility in the synthesis media. Li and Ragauskas [66] described a method for chemical modification of pine Kraft lignin to obtain a liquid polyol by means of oxypropylation with propylene oxide (PO) for synthesis of rigid polyurethane foam, where a total $\mathrm{OH}$ concentration of $6.9 \mathrm{mmol} / \mathrm{g}$ lignin was obtained compared to a concentration of $5.62 \mathrm{mmol} / \mathrm{g}$ lignin without oxypropylation. The oxypropylation of lignin allowed incorporating a higher lignin content in the formulation of the foams, even only using the polyols from lignin in reaction with the MDI di-isocyanate polymer. The mechanical properties of the rigid PU foams obtained using lignin improved considerably in strength index (0.14 MPa) and compression modulus (3.41 MPa). Ligno-polyurethane materials have been developed by de Oliveira et al. [67], using mixtures of oxypropylated lignosulfonates and castor oil rich in hydroxyl groups and where it was hypothesized that this modification would increase its reactivity towards methylene diphenyl isocyanate (MDI). The synthesized lignopolyurethane product presented high impact resistance and modulus of elasticity compared to composites prepared with lignosulfonates without oxypropyl [67]. In the same way, authors have prepared foams using different molar proportions of $\mathrm{NCO}: \mathrm{OH}$, and different fractions of lignins for the production of polyols from lignin modified by esterification with chlorinated fatty acid in a solvent-free system $[1,10]$. Increasing the use of lignin in foam preparations has been shown to increase the tensile strength and deformability of synthesized polyurethanes. This confirms the importance of the chemical and structural properties of lignin, such as available hydroxyl groups, molar mass, reactivity for the optimization of the stoichiometry in polyurethane foam preparations $[10,67,68]$. 


\subsection{Lignin-Based Carbon Fibers}

Carbon fibers (CFs) are one of the most advanced engineering products currently produced. CFs are composite products that are used in the transportation industry, manufacture of sports equipment, and construction $[1,69]$. The carbon fibers exhibit a unique combination of properties, such as lightness, high strength, flexibility, and resistance to fatigue, which makes them suitable for a wide range of applications.

Polyacrylonitrile (PAN) and regenerated cellulose are the primary precursors of current $\mathrm{CFs}$ production. Its manufacture involves melting or wet spinning, oxidative stabilization, and carbonization under an inert atmosphere, followed by surface and dimension treatment. Due to its low cost, lignin has a significant interest as a raw material for CFs production $[1,21,69]$. Different authors have been able to synthesize products based mainly on mixtures of Kraft lignin and polyethylene oxide (PO) through thermal spinning and subsequent carbonization [12,69,70]. Kadla et al. [69] manufactured carbon fibers with PO and Kraft lignin where the tensile strength obtained was 300-450 MPa and the modulus of elasticity 30-60 GPa, properties that where similar to the conventional carbon fibers. Liu et al. [71] propose the synthesis of the carbon fiber precursor prepared from lignosulfonate, acrylonitrile, and itaconic acid, called LS-AN-IA terpolymer. The thermal stability of the precursor fibers could lead to a decrease in the temperature and reaction times of the CFs synthesis process. The fibers obtained from the precursor LS-AN-IA resulted in good tensile strength $(1.74 \mathrm{GPa})$ and tensile modulus (210 GPa). Moreover, different proportions of organosolv lignin were tested by Hosseinaei et al. [70] to improve the spinning process, stabilization, and the properties of the $\mathrm{CFs}$, obtaining thermal stabilization even with the highest proportions of lignin (50\%). However, the glass transition temperatures were decreased using higher proportions than $50 \%$ of lignin, starting at $127^{\circ} \mathrm{C}(50 \%)$ until reaching $122^{\circ} \mathrm{C}(85 \%)$. Liu et al. [72] prepared mixtures of carbon fibers containing alkaline lignin and PAN (1:2 ratio), and carbon nanotubes through electric spinning. The carbonization process was carried out at $1100{ }^{\circ} \mathrm{C}$. The fibers obtained had a resistance of $1720 \mathrm{MPa}$ and a modulus of elasticity of $230 \mathrm{GPa}$, characteristics comparable to those that use PAN (1600 MPa and $223 \mathrm{GPa}$, respectively). In general, the use of lignin for CFs preparations would have the advantages of reducing production costs, synthesis times, and negative impacts on the environment. However, there is a need to obtain high-purity and high-quality lignin to reach high-performance $\mathrm{CF}$ results to compete with products synthesized that using PAN [12].

\subsection{Lignin-Based Hydrogels}

Polymeric materials as hydrogels have potential application in environmental, biological, and pharmaceutical fields $[29,68]$. Hydrogels are polymeric structures that have the capacity to swell up to a several times their weight without dissolving. These structural networks have hydrophilic groups to absorb water giving the form of a hydrogel. The most widely methods used for the synthesis of hydrogels are free radical polymerization, crosslinking covalent, and physical crosslinking. The polymers mainly used in hydrogels include poly (2-polyhydroxyethyl methacrylate) (PHEMA), polyethyl methacrylate (PEMA), polyacrylamide (PAAm), polymethacrylic acid (PMA), polyacrylic acid (PAA), polyglucoesiletil methacrylate (PGEMA), and polyhydroxypropyl methacrylamide (PHPMA) [21,29].

The interest in using lignin in hydrogels is mainly based on the biopolymer advantages, as biodegradability, low toxicity, environmentally friendly, and suitable for enzymatic degradation [29]. Some authors have carried out the application of organosolv lignin in the synthesis of hydrogels, based on the polymerization with $\mathrm{N}$-isopropylacrylamide in the presence of $N, N^{\prime}$-methylenebisacrylamide, as well as the use of Kraft lignin for the incorporation of diazobenzene groups [12].

Lignin-based hydrogels have also been studied for the supply of polyphenolic molecules. Ciolacu et al. [73] proposed superabsorbent hydrogels based on cellulose/lignin mixtures. The synthesis process consisted of dissolving cellulose in an alkaline medium and then 
incorporating lignin, according to the crosslinking process using epichlorohydrin. Through DSC analysis, the crosslinking was determined between lignin and cellulose using a formulation of $50 \%$ of each component at $80{ }^{\circ} \mathrm{C}$. These synthesized hydrogels would have potential applications in the biomedical area for the supply of polyphenolic structures $[67,73]$. Another application of lignin-based hydrogels was developed for agricultural use where lignin-based alginate hydrogels were studied for the controlled release of the insecticide azadirachtin [74]. The modified lignin hydrogels had a trapping efficiency of the insecticide of $99.5 \%$. Adding lignin to the hydrogel protects the insecticide from photodegradation, helping to maintain it active for a higher time [74]. In the field of water resources, the work developed by Mazloom et al. [75] describe a solution method to reduce the impact of water scarcity on agricultural soils, using a superabsorbent and biodegradable hydrogel based on alkali lignin to retain moisture from irrigation or rain, releasing water depending on the water demand of the soil and crops. In the results reported by Mazloom et al. [75], it was shown that maize crop plants were taller, had a higher amount of phosphorus, and a higher biomass when they were grown in soils with lignin hydrogels, compared to synthetic hydrogels and no hydrogels. Additionally, it was suggested that the addition of alkaline lignin to the soil of some crops could promote the activity of the roots due to the stimulation of specific phytohormones in plants, improving growth and elongation of plant stems $[75,76]$.

\subsection{Lignin-Based Composites and 3D Printing}

There has been a growing interest in the incorporation of lignin in thermoplastic materials, that can be used for the formulation of composites or biocomposites by 3D-printing in combination with other biopolymers such as polylactic acid (PLA), polyhydroxybutyrate (PHB), acrylonitrile butadiene styrene (ABS), and polyethylene (PE), with the aim to provide biodegradable properties, antimicrobial capacity, UV radiation stabilizer, and antioxidant activity properties [5,6,77-80]. Antioxidant materials can contribute to reduce the specific concentration of free radicals and active oxygen species, and lignin can provide some of these antioxidant activity properties. Domínguez-Robles et al. [81] developed composites made from PLA and lignin and demonstrated that the manufactured materials presented antioxidant activity achieving a decrease in the DPPH (2,2-diphenyl-1pycrylhydrazyl) compound of up to $80 \%$ after $5 \mathrm{~h}$ of application. Recent research reported the use of modified or unmodified lignin as reinforcing material in thermoplastic composites. Gordobil et al. [77] used acetylated and non-acetylated Kraft lignin for the elaboration of composites with PLA through extrusion of the components at $200{ }^{\circ} \mathrm{C}$. The presence of lignin in the composites increased the thermal stability of PLA and its hydrophobicity measured by contact angle. It was determined that the presence of low lignin contents $(<10 \%)$ did not affect the mechanical properties of the composites, rather there was an increase in the elongation index at break using the two types of lignin [77].

The FDM method (fused deposition modeling) has been widely used for the development of additive manufacturing for 3D printing [81]. Polylactic acid (PLA) is one of the biopolymers used for 3D printing, which is obtained from natural sources, being biodegradable and biocompatible $[5,6,80]$. However, the use of PLA has some disadvantages such as sensitivity to humidity, low glass transition temperature, low mechanical performance at elongation. Incorporate other biopolymers, like lignin, into the formulation of filaments for $3 \mathrm{D}$ printing emerges as an excellent alternative. Results reported by Tanase-Opedal et al. [6] described a method for obtaining filaments based on PLA and softwood lignin from soda pulping process in proportions between $20-40 \%$. Authors described a nucleating phenomenon of lignin in the mixture with PLA, which facilitated the crystallization of PLA in the elaboration of the filaments. In mechanical tests, PLA/lignin biocomposites were shown to have a similar tensile elastic modulus index $(\mathrm{Et}=2695 \mathrm{MPa})$ vs. biocomposites that only had PLA $(\mathrm{Et}=2890 \mathrm{MPa})$ using a printing at $215^{\circ} \mathrm{C}$. Although the integration of lignin into the biocomposites could reduce the tensile strength modulus, this mechanical property can be improved optimizing the 3D printing temperatures. In 
the biocomposites based on PLA/lignin, an important antioxidant activity was observed, increased by $50 \%$ in the composite made with $40 \%$ of lignin. Furthermore, the developed PLA/lignin biocomposites exhibited good extrudability and flowability without lignin agglomerations [6].

Nguyen et al. [79] developed an additive manufacturing system using organosolv and Kraft lignin in different mixtures of acrylonitrile-butadiene-styrene (ABS) polymer and nylon. These mixtures were used to elaborate materials by $3 \mathrm{D}$ printing using the FDM method, where a proportion of lignin between $40-60 \%$ in weight was employed. The resulting composite with the best performance and with promising properties was obtained in a mixture of nylon 12 and hardwood organosolv lignin. This composite had high stiffness and tensile strength at room temperature. Vaidya et al. [78] prepared composites based on polyhydroxybuirate (PHB) softwood lignin as a non-reactive filler without any derivatization or chemical modification. The biocomposite was developed by extrusion to form filaments for 3D-printing by FDM. Biocomposites with PHB and 50\% lignin presented an increased contact angle to $72.8^{\circ}$ vs. $46.4^{\circ}$ in the pure PHB biocomposite, improving the hidrofobicity of the biocomsites. Besides, the incorporation from $20 \%$ lignin as filler in the filament could benefit the printability and reduction of the shrinkage during the filament impression.

Mimini et al. [5] studied the compatibility of three types of lignins (organosolv, Kraft, and lignosulfonate) in mixtures with PLA to produce biocomposites by 3D-printing. The results showed that the mixtures between PLA and organosolv lignin exhibited better flexural resistance than those made with Kraft lignin or lignosulfonate with a maximum of $100 \mathrm{MPa}$ using $5 \%$ organosolv lignin, a value almost identical to that obtained only with PLA. In addition, the mixture between PLA/organosolv lignin had better thermal resistance compared with the other lignins determined by thermogravimetric analysis (TGA). The high compatibility between organosolv lignin and PLA could be attributed to its low molecular weight (Mw $1200 \mathrm{~g} / \mathrm{mol} \mathrm{vs.} \mathrm{Mw} 4000 \mathrm{~g} / \mathrm{mol}$ in the other lignins) being a suitable compound to be incorporated in extrusion and 3D printing systems [5].

\section{Outlook}

The aromatic structure and diversity of lignin functional groups have opened a way to valorize and use this natural polymer. This review presented different routes for incorporating lignin, which is also a by-product of the pulp and paper industry, in different materials to replace petroleum-derived chemical reagents and prepolymers. Although it is possible to generate high-value added materials using the different lignins, it is still necessary to improve some fundamental properties of lignin-derived products to compete with chemicals derived from petroleum and make them commercially attractive for the chemical industry. In this sense, obtain a highly homogeneous molecular weight distribution, increase the quantity of hydroxyl groups, and increase in solubility are some of the priorities. Achieving effective lignin deconstruction mechanisms and optimizing the conversion of lignin in the desired phenolic chemical structures are the main challenges. Catalytic processes can be used by combining chemical, enzymatic, or physical mechanisms to improve the effectiveness of depolymerization or lignin conversion. The next challenges for this natural compound are correlated with the development of eco-efficient and sustainable technological processes. In this way, lignin can become in a wide platform of resources and raw materials for various industrial sectors that are directed towards eco-friendly processes. For example, some potential new applications for lignin are: production of nano-scale structures for the metal absorption in water or air pollutants capture; generation of inexpensive-effective pyrolysis processes to obtain simple compounds as industrial solvents to replace petroleum-derived compounds such as toluene, xylene, and benzene; or development of 3D printing materials designed for biomedical applications (artificial tissues as support for antioxidant, antimicrobial, or biodegradable compounds from lignin). Optimizing the catalytic mechanisms using lignin as raw material will facilitate the development of improved sustainable materials. Applying these innovative products on an 
industrial scale with commercial attractiveness will depend on a cost-effective feedstock. Aims these clear goals, lignin will become a great alternative as a renewable chemical for the industry into the bioeconomy concept.

Author Contributions: Conceptualization, F.V.-G. and R.T.M.; Methodology, F.V.-G., I.C.-V., C.V. and P.R.-C.; Software, F.V.-G.; Formal Analysis, F.V.-G. and P.R.-C.; Investigation, F.V.-G., I.C.-V., C.V. and P.R.-C.; Data Curation, F.V.-G., I.C.-V. and P.R.-C.; Writing-Original Draft Preparation, F.V.-G., I.C.-V., P.R.-C. and C.V.; Writing-Review \& Editing, R.T.M., M.F. and P.R.-C.; Supervision, R.T.M. and P.R.-C.; Project Administration, R.T.M. and M.F.; Funding Acquisition, F.V.-G., I.C.-V., C.V. and M.F. All authors have read and agreed to the published version of the manuscript.

Funding: This research was funded by CONICYT under Grant No. 21130772 and Grant No. 21202180, by ANID/Fondecyt-Postdoctoral Grant No. 3200114, by CORFO under Grant No. 13CEI2-21839, and by VRID-UdeC under Grant No. 219.141.023-P.

Institutional Review Board Statement: Not applicable.

Informed Consent Statement: Not applicable.

Data Availability Statement: All data generated or analyzed during this research are included in this published article.

Acknowledgments: F. Vásquez-Garay was supported by CONICYT (Doctoral grant No. 21130772) and the Innovation Found for Competitiveness of the Chilean Economic Development Agency (CORFO) under Grant No. 13CEI2-21839. I. Carrillo-Varela thanks VRID-UdeC/Postdoctoral grant (No. 219.141.023-P) and ANID/Fondecyt-Postdoctoral grant (No. 3200114). C. Vidal thanks CONICYT (Doctoral grant No. 21202180).

Conflicts of Interest: The authors declare no conflict of interest.

\section{References}

1. Laurichesse, S.; Avérous, L. Chemical Modification of Lignins: Towards Biobased Polymers. Prog. Polym. Sci. 2014, 39, 1266-1290. [CrossRef]

2. Abdelaziz, O.Y.; Brink, D.P.; Prothmann, J.; Ravi, K.; Sun, M.; García-Hidalgo, J.; Sandahl, M.; Hulteberg, C.P.; Turner, C.; Lidén, G.; et al. Biological Valorization of Low Molecular Weight Lignin. Biotechnol. Adv. 2016, 34, 1318-1346. [CrossRef] [PubMed]

3. Lange, H.; Decina, S.; Crestini, C. Oxidative Upgrade of Lignin-Recent Routes Reviewed. Eur. Polym. J. 2013, 49, 1151-1173. [CrossRef]

4. Gall, D.L.; Ralph, J.; Donohue, T.J.; Noguera, D.R. Biochemical Transformation of Lignin for Deriving Valued Commodities from Lignocellulose. Curr. Opin. Biotechnol. 2017, 45, 120-126. [CrossRef] [PubMed]

5. Mimini, V.; Sykacek, E.; Hashim, S.N.A.; Holzweber, J.; Hettegger, H.; Fackler, K.; Potthast, A.; Mundigler, N.; Rosenau, T. Compatibility of Kraft Lignin, Organosolv Lignin and Lignosulfonate with PLA in 3D Printing. J. Wood Chem. Technol. 2019, 39, 14-30. [CrossRef]

6. Tanase-Opedal, M.; Espinosa, E.; Rodríguez, A.; Chinga-Carrasco, G. Lignin: A Biopolymer from Forestry Biomass for Biocomposites and 3D Printing. Materials 2019, 12, 3006. [CrossRef]

7. Wang, H.; Pu, Y.; Ragauskas, A.; Yang, B. From Lignin to Valuable Products—Strategies, Challenges, and Prospects. Bioresour. Technol. 2019, 271, 449-461. [CrossRef]

8. Upton, B.M.; Kasko, A.M. Strategies for the Conversion of Lignin to High-Value Polymeric Materials: Review and Perspective. Chem. Rev. 2016, 116, 2275-2306. [CrossRef] [PubMed]

9. Constant, S.; Wienk, H.L.J.; Frissen, A.E.; de Peinder, P.; Boelens, R.; van Es, D.S.; Grisel, R.J.H.; Weckhuysen, B.M.; Huijgen, W.J.J.; Gosselink, R.J.A.; et al. New Insights into the Structure and Composition of Technical Lignins: A Comparative Characterization Study. Green Chem. 2016, 18, 2651-2665. [CrossRef]

10. Naseem, A.; Tabasum, S.; Zia, K.M.; Zuber, M.; Ali, M.; Noreen, A. Lignin-Derivatives Based Polymers, Blends and Composites: A Review. Int. J. Biol. Macromol. 2016, 93, 296-313. [CrossRef] [PubMed]

11. Ragauskas, A.J.; Beckham, G.T.; Biddy, M.J.; Chandra, R.; Chen, F.; Davis, M.F.; Davison, B.H.; Dixon, R.A.; Gilna, P.; Keller, M.; et al. Lignin Valorization: Improving Lignin Processing in the Biorefinery. Science 2014, 344. [CrossRef]

12. Kun, D.; Pukánszky, B. Polymer/Lignin Blends: Interactions, Properties, Applications. Eur. Polym. J. 2017, 93, 618-641. [CrossRef]

13. Zinovyev, G.; Sumerskii, I.; Korntner, P.; Sulaeva, I.; Rosenau, T.; Potthast, A. Molar Mass-Dependent Profiles of Functional Groups and Carbohydrates in Kraft Lignin. J. Wood Chem. Technol. 2017, 37, 171-183. [CrossRef]

14. Hodásová, L.; Jablonský, M.; Škulcová, A.; Ház, A. Lignin, Potential Products and Their Market Value. Wood Res. 2015, 60, 973-986. 
15. Gauss, C.; Pickering, K.L.; Muthe, L.P. The Use of Cellulose in Bio-derived Formulations for 3D/4D printing: A review. Compos. Part C Open Access 2021, 4, 100113. [CrossRef]

16. Limayem, A.; Ricke, S.C. Lignocellulosic Biomass for Bioethanol Production: Current Perspectives, Potential Issues and Future Prospects. Prog. Energy Combust. Sci. 2012, 38, 449-467. [CrossRef]

17. Doherty, W.O.S.; Mousavioun, P.; Fellows, C.M. Value-Adding to Cellulosic Ethanol: Lignin Polymers. Ind. Crop. Prod. 2011, 33, 259-276. [CrossRef]

18. Xu, C.; Arancon, R.A.D.; Labidi, J.; Luque, R. Lignin Depolymerisation Strategies: Towards Valuable Chemicals and Fuels. Chem. Soc. Rev. 2014, 43, 7485-7500. [CrossRef] [PubMed]

19. Boerjan, W.; Ralph, J.; Baucher, M. Lignin Biosynthesis. Annu. Rev. Plant Biol. 2003, 54, 519-546. [CrossRef] [PubMed]

20. Bonawitz, N.D.; Chapple, C. The Genetics of Lignin Biosynthesis: Connecting Genotype to Phenotype. Annu. Rev. Genet. 2010, 44, 337-363. [CrossRef] [PubMed]

21. Peretti, S.; Barton, R.; Mendonça, R. Lignin as Feedstock for Fibers and Chemicals. In Commercializing Biobased Products: Opportunities, Challenges, Benefits, and Risks; Royal Society of Chemistry: Cambridge, UK, 2016; pp. 132-165.

22. Ralph, J.; Lundquist, K.; Brunow, G.; Lu, F.; Kim, H.; Schatz, P.F.; Marita, J.M.; Hatfield, R.D.; Ralph, S.A.; Christensen, J.H.; et al. Lignins: Natural Polymers from Oxidative Coupling of 4-Hydroxyphenyl- Propanoids. Phytochem. Rev. 2004, 3, 29-60. [CrossRef]

23. Ralph, J. Hydroxycinnamates in Lignification. Phytochem. Rev. 2010, 9, 65-83. [CrossRef]

24. Abdel-Hamid, A.M.; Solbiati, J.O.; Cann, I.K.O. Insights into Lignin Degradation and Its Potential Industrial Applications. In Advances in Applied Microbiology; Academic Press: Cambridge, MA, USA, 2013; Volume 82, pp. 1-28.

25. Rencoret, J.; Gutiérrez, A.; Nieto, L.; Jiménez-Barbero, J.; Faulds, C.B.; Kim, H.; Ralph, J.; Martínez, Á.T.; del Río, J.C. Lignin Composition and Structure in Young versus Adult Eucalyptus globulus Plants on JSTOR. Plant. Physiol. 2011, 155, 667-682. [CrossRef] [PubMed]

26. Saito, K.; Horikawa, Y.; Sugiyama, J.; Watanabe, T.; Kobayashi, Y.; Takabe, K. Effect of Thermochemical Pretreatment on Lignin Alteration and Cell Wall Microstructural Degradation in Eucalyptus globulus: Comparison of Acid, Alkali, and Water Pretreatments. J. Wood Sci. 2016, 62, 276-284. [CrossRef]

27. Calvo-Flores, F.G.; Dobado, J.A. Lignin as Renewable Raw Material. ChemSusChem 2010, 3, 1227-1235. [CrossRef] [PubMed]

28. Li, C.; Zhao, X.; Wang, A.; Huber, G.W.; Zhang, T. Catalytic Transformation of Lignin for the Production of Chemicals and Fuels. Chem. Rev. 2015, 115, 11559-11624. [CrossRef] [PubMed]

29. Thakur, V.K.; Thakur, M.K. Recent Advances in Green Hydrogels from Lignin: A Review. Int. J. Biol. Macromol. 2015, 72, 834-847. [CrossRef] [PubMed]

30. Zakzeski, J.; Bruijnincx, P.C.A.; Jongerius, A.L.; Weckhuysen, B.M. The Catalytic Valorization of Lignin for the Production of Renewable Chemicals. Chem. Rev. 2010, 110, 3552-3599. [CrossRef] [PubMed]

31. Galkin, M.V.; Samec, J.S.M. Lignin Valorization through Catalytic Lignocellulose Fractionation: A Fundamental Platform for the Future Biorefinery. ChemSusChem 2016, 9, 1544-1558. [CrossRef]

32. Smook, G.A. Handbook for Pulp and Paper Technologies, 3rd ed.; Angus Wilde Publications, Inc.: Vancouver, BC, Canada, 2002.

33. Sjöström, E. (Ed.) Wood-Based Chemicals and Pulping By-Products. In Wood Chemistry: Fundamentals and Applications; Academic Press: San Diego, CA, USA, 1993; pp. 225-248. ISBN 978-0-08-092589-9.

34. Reyes, P.; Márquez, N.; Troncoso, E.; Parra, C.; Mendonça, R.T.; Rodríguez, J. Evaluation of Combined Dilute Acid-Kraft and Steam Explosion-Kraft Processes as Pretreatment for Enzymatic Hydrolysis of Pinus radiata Wood Chips. BioResources 2016, 11, 612-625. [CrossRef]

35. Mahmood, N.; Yuan, Z.; Schmidt, J.; Xu, C. Depolymerization of Lignins and Their Applications for the Preparation of Polyols and Rigid Polyurethane Foams: A Review. Renew. Sustain. Energy Rev. 2016, 60, 317-329. [CrossRef]

36. Mood, S.H.; Golfeshan, A.H.; Tabatabaei, M.; Jouzani, G.S.; Najafi, G.H.; Gholami, M.; Ardjmand, M. Lignocellulosic Biomass to Bioethanol, a Comprehensive Review with a Focus on Pretreatment. Renew. Sustain. Energy Rev. 2013, 27, 77-93. [CrossRef]

37. Pan, X.; Arato, C.; Gilkes, N.; Gregg, D.; Mabee, W.; Pye, K.; Xiao, Z.; Zhang, X.; Saddler, J. Biorefining of Softwoods Using Ethanol Organosolv Pulping: Preliminary Evaluation of Process Streams for Manufacture of Fuel-Grade Ethanol and Co-Products. Biotechnol. Bioeng. 2005, 90, 473-481. [CrossRef] [PubMed]

38. Alvira, P.; Tomás-Pejó, E.; Ballesteros, M.; Negro, M.J. Pretreatment Technologies for an Efficient Bioethanol Production Process Based on Enzymatic Hydrolysis: A Review. Bioresour. Technol. 2010, 101, 4851-4861. [CrossRef] [PubMed]

39. Graichen, F.H.M.; Grigsby, W.J.; Hill, S.J.; Raymond, L.G.; Sanglard, M.; Smith, D.A.; Thorlby, G.J.; Torr, K.M.; Warnes, J.M. Yes, We Can Make Money out of Lignin and Other Bio-Based Resources. Ind. Crop. Prod. 2017, 106, 74-85. [CrossRef]

40. Çetin, N.S.; Özmen, N. Use of Organosolv Lignin in Phenol-Formaldehyde Resins for Particleboard Production: II. Particleboard Production and Properties. Int. J. Adhes. Adhes. 2002, 22, 481-486. [CrossRef]

41. Zhang, W.; Ma, Y.; Wang, C.; Li, S.; Zhang, M.; Chu, F. Preparation and Properties of Lignin-Phenol-Formaldehyde Resins Based on Different Biorefinery Residues of Agricultural Biomass. Ind. Crop. Prod. 2013, 43, 326-333. [CrossRef]

42. Qiao, W.; Li, S.; Guo, G.; Han, S.; Ren, S.; Ma, Y. Synthesis and Characterization of Phenol-Formaldehyde Resin Using Enzymatic Hydrolysis Lignin. J. Ind. Eng. Chem. 2015, 21, 1417-1422. [CrossRef]

43. Kalami, S.; Arefmanesh, M.; Master, E.; Nejad, M. Replacing 100\% of Phenol in Phenolic Adhesive Formulations with Lignin. J. Appl. Polym. Sci. 2017, 134, 45124. [CrossRef] 
44. Raquez, J.M.; Deléglise, M.; Lacrampe, M.F.; Krawczak, P. Thermosetting (Bio)Materials Derived from Renewable Resources: A Critical Review. Prog. Polym. Sci. 2010, 35, 487-509. [CrossRef]

45. Wang, M.; Leitch, M.; Xu, C. Synthesis of Phenol-Formaldehyde Resol Resins Using Organosolv Pine Lignins. Eur. Polym. J. 2009, 45, 3380-3388. [CrossRef]

46. Jing, Z.; Lihong, H.; Bingchuan, L.; Caiying, B.; Puyou, J.; Yonghong, Z. Preparation and Characterization of Novolac PhenolFormaldehyde Resins with Enzymatic Hydrolysis Lignin. J. Taiwan Inst. Chem. Eng. 2015, 54, 178-182. [CrossRef]

47. El Mansouri, N.E.E.; Salvadó, J. Structural Characterization of Technical Lignins for the Production of Adhesives: Application to Lignosulfonate, Kraft, Soda-Anthraquinone, Organosolv and Ethanol Process Lignins. Ind. Crop. Prod. 2006, 24, 8-16. [CrossRef]

48. Pang, B.; Yang, S.; Fang, W.; Yuan, T.Q.; Argyropoulos, D.S.; Sun, R.C. Structure-Property Relationships for Technical Lignins for the Production of Lignin-Phenol-Formaldehyde Resins. Ind. Crop. Prod. 2017, 108, 316-326. [CrossRef]

49. El Mansouri, N.E.; Yuan, Q.; Huang, F. Synthesis and Characterization of Kraft Lignin-Based Epoxy Resins. BioResources 2011, 6, 2492-2503. [CrossRef]

50. Li, K.; Geng, X. Formaldehyde-Free Wood Adhesives from Decayed Wood. Macromol. Rapid Commun. 2005, 26, 529-532. [CrossRef]

51. Jang, Y.; Huang, J.; Li, K. A New Formaldehyde-Free Wood Adhesive from Renewable Materials. Int. J. Adhes. Adhes. 2011, 31, 754-759. [CrossRef]

52. Gong, X.; Liu, T.; Yu, S.; Meng, Y.; Lu, J.; Cheng, Y.; Wang, H. The Preparation and Performance of a Novel Lignin-Based Adhesive without Formaldehyde. Ind. Crop. Prod. 2020, 153, 112593. [CrossRef]

53. Liu, Y.; Li, K. Preparation and Characterization of Demethylated Lignin-Polyethylenimine Adhesives. J. Adhes. 2006, 82, 593-605. [CrossRef]

54. Younesi-Kordkheili, H.; Pizzi, A. Improving the Properties of Urea-Lignin-Glyoxal Resin as a Wood Adhesive by Small Addition of Epoxy. Int. J. Adhes. Adhes. 2020, 102, 102681. [CrossRef]

55. Törnvall, U.; Orellana-Coca, C.; Hatti-Kaul, R.; Adlercreutz, D. Stability of Immobilized Candida antarctica Lipase B during Chemo-Enzymatic Epoxidation of Fatty Acids. Enzym. Microb. Technol. 2007, 40, 447-451. [CrossRef]

56. Aouf, C.; Lecomte, J.; Villeneuve, P.; Dubreucq, E.; Fulcrand, H. Chemo-Enzymatic Functionalization of Gallic and Vanillic Acids: Synthesis of Bio-Based Epoxy Resins Prepolymers. Green Chem. 2012, 14, 2328-2336. [CrossRef]

57. Vásquez-Garay, F.; Mendonça, R.T.; Peretti, S.W. Chemoenzymatic Lignin Valorization: Production of Epoxidized Pre-Polymers Using Candida Antarctica Lipase B. Enzym. Microb. Technol. 2018, 112, 6-13. [CrossRef]

58. Vandenberg, L.N.; Hauser, R.; Marcus, M.; Olea, N.; Welshons, W.V. Human Exposure to Bisphenol A (BPA). Reprod. Toxicol. 2007, 24, 139-177. [CrossRef] [PubMed]

59. Huang, Y.Q.; Wong, C.K.C.; Zheng, J.S.; Bouwman, H.; Barra, R.; Wahlström, B.; Neretin, L.; Wong, M.H. Bisphenol A (BPA) in China: A Review of Sources, Environmental Levels, and Potential Human Health Impacts. Environ. Int. 2012, 42, 91-99. [CrossRef]

60. Aouf, C.; Nouailhas, H.; Fache, M.; Caillol, S.; Boutevin, B.; Fulcrand, H. Multi-Functionalization of Gallic Acid. Synthesis of a Novel Bio-Based Epoxy Resin. Eur. Polym. J. 2013, 49, 1185-1195. [CrossRef]

61. Maćczak, A.; Bukowska, B.; Michalowicz, J. Comparative Study of the Effect of BPA and Its Selected Analogues on Hemoglobin Oxidation, Morphological Alterations and Hemolytic Changes in Human Erythrocytes. Comp. Biochem. Physiol. Part C Toxicol. Pharmacol. 2015, 176, 62-70. [CrossRef]

62. Chua, S.C.; Xu, X.; Guo, Z. Emerging Sustainable Technology for Epoxidation Directed toward Plant Oil-Based Plasticizers. Process. Biochem. 2012, 47, 1439-1451. [CrossRef]

63. Jablonskis, A.; Arshanitsa, A.; Arnautov, A.; Telysheva, G.; Evtuguin, D. Evaluation of Ligno Boost ${ }^{\mathrm{TM}}$ Softwood Kraft Lignin Epoxidation as an Approach for Its Application in Cured Epoxy Resins. Ind. Crop. Prod. 2018, 112, 225-235. [CrossRef]

64. Gómez-Fernández, S.; Ugarte, L.; Calvo-Correas, T.; Peña-Rodríguez, C.; Corcuera, M.A.; Eceiza, A. Properties of Flexible Polyurethane Foams Containing Isocyanate Functionalized Kraft Lignin. Ind. Crop. Prod. 2017, 100, 51-64. [CrossRef]

65. Pan, X.; Saddler, J.N. Effect of Replacing Polyol by Organosolv and Kraft Lignin on the Property and Structure of Rigid Polyurethane Foam. Biotechnol. Biofuels 2013, 6, 12. [CrossRef]

66. Li, Y.; Ragauskas, A.J. Kraft Lignin-Based Rigid Polyurethane Foam. J. Wood Chem. Technol. 2012, 32, 210-224. [CrossRef]

67. de Oliveira, F.; Ramires, E.C.; Frollini, E.; Belgacem, M.N. Lignopolyurethanic Materials Based on Oxypropylated Sodium Lignosulfonate and Castor Oil Blends. Ind. Crop. Prod. 2015, 72, 77-86. [CrossRef]

68. Figueiredo, P.; Lintinen, K.; Hirvonen, J.T.; Kostiainen, M.A.; Santos, H.A. Properties and Chemical Modifications of Lignin: Towards Lignin-Based Nanomaterials for Biomedical Applications. Prog. Mater. Sci. 2018, 93, 233-269. [CrossRef]

69. Kadla, J.F.; Kubo, S.; Venditti, R.A.; Gilbert, R.D.; Compere, A.L.; Griffith, W. Lignin-Based Carbon Fibers for Composite Fiber Applications. Carbon 2002, 40, 2913-2920. [CrossRef]

70. Hosseinaei, O.; Harper, D.P.; Bozell, J.J.; Rials, T.G. Improving Processing and Performance of Pure Lignin Carbon Fibers through Hardwood and Herbaceous Lignin Blends. Int. J. Mol. Sci. 2017, 18, 1410. [CrossRef] [PubMed]

71. Liu, D.; Ouyang, Q.; Jiang, X.; Ma, H.; Chen, Y.; He, L. Thermal Properties and Thermal Stabilization of LignosulfonateAcrylonitrile-Itaconic Acid Terpolymer for Preparation of Carbon Fiber. Polym. Degrad. Stab. 2018, 150, 57-66. [CrossRef]

72. Liu, H.C.; Chien, A.T.; Newcomb, B.A.; Liu, Y.; Kumar, S. Processing, Structure, and Properties of Lignin- and CNT-Incorporated Polyacrylonitrile-Based Carbon Fibers. ACS Sustain. Chem. Eng. 2015, 3, 1943-1954. [CrossRef]

73. Ciolacu, D.; Oprea, A.M.; Anghel, N.; Cazacu, G.; Cazacu, M. New Cellulose-Lignin Hydrogels and Their Application in Controlled Release of Polyphenols. Mater. Sci. Eng. C 2012, 32, 452-463. [CrossRef] 
74. Flores-Céspedes, F.; Martínez-Domínguez, G.P.; Villafranca-Sánchez, M.; Fernández-Pérez, M. Preparation and Characterization of Azadirachtin Alginate-Biosorbent Based Formulations: Water Release Kinetics and Photodegradation Study. J. Agric. Food Chem. 2015, 63, 8391-8398. [CrossRef] [PubMed]

75. Mazloom, N.; Khorassani, R.; Zohury, G.H.; Emami, H.; Whalen, J. Lignin-Based Hydrogel Alleviates Drought Stress in Maize. Environ. Exp. Bot. 2020, 175, 104055. [CrossRef]

76. Lv, T.; Yang, H.; Zhang, R.; Fan, W.; Xu, Y.; Cao, H.; Ning, L.; Zhou, C.; Wang, L. Effects of Lignin on Root Activity and Soil Nutrients of Malus hupehensis. Var. Pingyiensis under the Use of Organic Fertilizer. Agric. Sci. 2017, 8, 341-347. [CrossRef]

77. Gordobil, O.; Delucis, R.; Egüés, I.; Labidi, J. Kraft Lignin as Filler in PLA to Improve Ductility and Thermal Properties. Ind. Crop. Prod. 2015, 72, 46-53. [CrossRef]

78. Vaidya, A.A.; Collet, C.; Gaugler, M.; Lloyd-Jones, G. Integrating Softwood Biorefinery Lignin into Polyhydroxybutyrate Composites and Application in 3D Printing. Mater. Today Commun. 2019, 19, 286-296. [CrossRef]

79. Nguyen, N.A.; Barnes, S.H.; Bowland, C.C.; Meek, K.M.; Littrell, K.C.; Keum, J.K.; Naskar, A.K. A Path for Lignin Valorization via Additive Manufacturing of High-Performance Sustainable Composites with Enhanced 3D Printability. Sci. Adv. 2018, 4, eaat4967. [CrossRef] [PubMed]

80. Cataldi, A.; Rigotti, D.; Nguyen, V.D.H.; Pegoretti, A. Polyvinyl Alcohol Reinforced with Crystalline Nanocellulose for 3D Printing Application. Mater. Today Commun. 2018, 15, 236-244. [CrossRef]

81. Domínguez-Robles, J.; Martin, N.; Fong, M.; Stewart, S.; Irwin, N.; Rial-Hermida, M.; Donnelly, R.; Larrañeta, E. Antioxidant PLA Composites Containing Lignin for 3D Printing Applications: A Potential Material for Healthcare Applications. Pharmaceutics 2019, 11, 165. [CrossRef] [PubMed] 